\title{
Review
}

\section{Skin manifestations of Bartonella infections}

\author{
César A. Chian, MD, Jorge E. Arrese, MD, PhD, and Gérald E. Piérard, MD, PhD
}

From the Department of Pathology, Universidad Peruana Cayetano Heredia, Lima, Peru and the Department of Dermatopathology, University Medical Center of Liège, Liège, Belgium

Correspondence to

G. E. Piérard, MD, PhD, Department Dermatopathology, CHU Sart Tilman, B-4000 Liège, Belgium

\section{Introduction}

The recognition of the bacteria family Bartonellaceae, genus Bartonella has expanded during the past decade from the single Bartonella bacilliformis to $\mathrm{I} 7$ currently identified species (Table I). At least six of these (B. bacilliformis, B. henselae, B. quintana, B. elizabethae, B. clarridgeiae and B. vinsonni arupensis) are responsible for human diseases. ${ }^{\mathrm{I}, 2}$ The growing knowledge in this field of pathology and the new insights provided by molecular biology suggest that the number of recognized Bartonella spp. and human diseases caused by them will continue to increase in the coming years.

This review focuses on the cutaneous manifestations of bartonelloses, emphasizing selected controversial topics about angiomatous skin lesions.

Table 1 Bartonella spp. pathogens in humans and animals. Adapted from $[\mathrm{I}, 2]$

\begin{tabular}{llll}
\hline Species & $\begin{array}{l}\text { Year of original } \\
\text { description }\end{array}$ & Hosts & $\begin{array}{l}\text { Arthropod } \\
\text { vector }\end{array}$ \\
\hline B. bacilliformis & 1907 & Human & Sandfly \\
B. talpae & 1911 & Mole & Body louse \\
B. quintana & 1917 & Human & \\
B. peromysci & 1942 & Deer, mouse & \\
B. vinsonni vinsonni & 1946 & Vole & Cat flea \\
B. henselae & 1992 & Cat, Human & \\
B. elizabethae & 1993 & Rat, Human & \\
B. grahamii & 1995 & Mouse, vole & \\
B. taylorii & 1995 & Mouse, vole & \\
B. doshiae & 1995 & Vole & \\
B. vinsonni berkhoffi & 1996 & Dog & \\
B. clarridgeiae & 1996 & Cat, Human & \\
B. tribocorum & 1998 & Rat & \\
B. alsatica & 1999 & Rabbit & \\
B. khoelerae & 1999 & Cat & \\
B. vinsonni arupensis & 1999 & Cattle, Human & \\
B. weissii & 2000 & Cattle, cat & \\
\hline
\end{tabular}

\section{Cat scratch disease}

Cat scratch disease (CSD) is the most common Bartonella infection worldwide. ${ }^{\mathrm{I}}$ In patients with history of cat contact or scratches, the disease typically presents as a lymphadenopathy preceded by an erythematous papule at the inoculation site (Fig. I). This cutaneous lesion develops 3- Io days after inoculation ${ }^{3}$ and usually evolves through erythematous, vesicular, and papular crusted stages, persisting for about I -3 weeks. ${ }^{4}$ Hence, it may still be present as a crusted erythematous papule $2-6 \mathrm{~mm}$ in diameter when the regional lymphadenopathy develops $3-50$ days after inoculation. The histopathology of the skin lesion is similar to the lymph node changes consisting of a diffuse inflammatory cell infiltrate associating numerous neutrophils and histiocytes admixed with scattered eosinophils and plasma cells. Epidermal hyperplasia and dermal deposits of proteoglycans may also be present in the skin. ${ }^{5}$ Warthin-Starry silver stain frequently

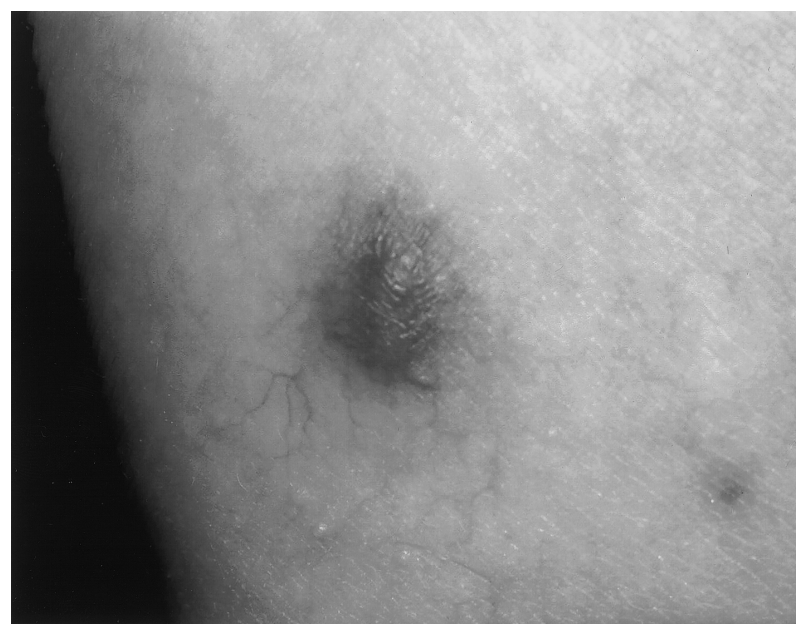

Figure 1 Cat scratch disease. Papular lesion at the inoculation site 
reveals clustered bacteria within micro-abscesses, with progressive clearing of these micro-organisms as the lesion resolves. ${ }^{5}$ Other, more unusual, skin manifestations include morbilliform eruptions, urticaria, erythema nodosum, erythema multiforme and erythema marginatum.

It is widely accepted that $B$. henselae is the primary etiologic agent of CSD. ${ }^{6}$ Although it is currently impossible to reproduce CSD in a host other than the cat to fulfill the Koch's postulates, 'evidence of causation' for B. henselae was demonstrated in CSD using molecular biology. ' However, two recent case reports identified $B$. clarridgeiae as the suspicious causative agent. ${ }^{8,9}$ There have also been cases without evidence of Bartonella infection despite appropriate search. For example, when immunofluorescence assay was applied to serum from patients with the most strictly defined CSD cases, $5-\mathrm{I} 5 \%$ of these samples yielded negative results. ${ }^{\mathrm{IO}}$ Finally, the role of Afipia felis, initially considered to be the cause of CSD, is not ruled out, it being possible that this and other bacteria may be involved in a small percentage of CSD cases. ${ }^{6}$

\section{Trench fever}

In the past, trench fever was one of the most widespread bartonelloses. Transmitted by the body louse, the disease became rare after World War II, but surged again during the last decade in poor, homeless, alcoholic men living in urban areas. ${ }^{\mathrm{II}}$ This disease, caused by B. quintana, follows a cyclic clinical evolution combining fever, malaise, chills, anorexia, sweating, headache, conjunctival injection, myalgias and arthralgias. About $80-90 \%$ of the patients present crops of erythematous macules or papules measuring $\mathrm{I} \mathrm{cm}$ or less on the abdomen, chest and back. ${ }^{2}$ These cutaneous manifestations have not been thoroughly studied using histopathology. As the condition is quite fleeting, it would be expected to demonstrate only minimal, if any vasculitis. ${ }^{5}$

\section{Bacillary angiomatosis}

The first case of bacillary angiomatosis (BA) was reported in an AIDS patient. ${ }^{\mathrm{I}}$. Nearly ro years later, $B$. henselae and $B$. quintana were demonstrated from cutaneous lesions and blood of affected individuals by direct cultivation and polymerase chain reaction (PCR)-amplification of specific gene sequences. ${ }^{{ }^{13}}$

AIDS-associated BA was most frequently seen when the $\mathrm{CD}_{4}$ count decreased to less than Ioo cells $/ \mathrm{mm} .^{\mathrm{I} 2, \mathrm{I} 4}$ It was also described in immunocompromised cardiac and renal transplant patients ${ }^{15}$ and in patients under chemotherapy for hematologic malignancies ${ }^{16}$ as well as in apparently immunocompetent individuals. ${ }^{17,18}$ Bacillary angiomatosis was identified in different tissues including skin, brain, bone, lymph nodes, gastrointestinal and respiratory tract and bone marrow. ${ }^{4,1_{5}}$

Epidemiological studies have shown skin lesions to be the most frequent clinical manifestation of the disease, ranging

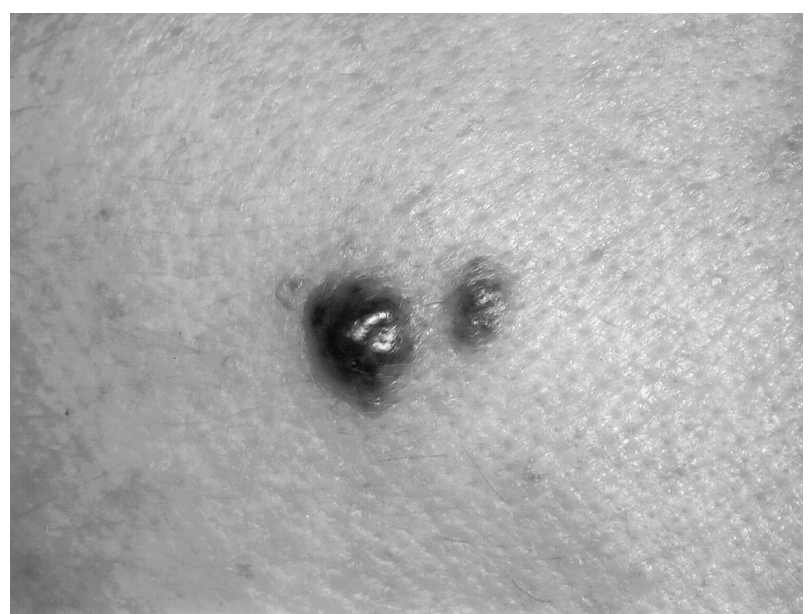

Figure 2 Bacillary angiomatosis in a cardiac transplant patient

from $55 \%$ to $90 \%$ of cases. ${ }^{14,19}$ It is noteworthy that the incidence of BA has been dramatically reduced since the introduction of AIDS tritherapy and prophylactic antibiotherapy. The typical lesion is solitary or dispersed all over the body. The reddish-purple papule about $\mathrm{I} \mathrm{cm}$ in diameter (Fig. 2) and may be difficult to differentiate clinically from Kaposi's disease, epithelioid hemangioma and pyogenic granuloma, ${ }^{6}$ making it mandatory to examine a skin biopsy to confirm the diagnosis. Other BA lesions present under different aspects including smooth, warty and pedunculated papules, as well as subcutaneous nodules and hyperkeratotic plaques. They are rarely ulcerated or bleeding.

\section{Etiology}

There is a current trend to curb the BA incidence, probably due to the extensive use of antimicrobial drugs as prophylactic agents in immunocompromised patients. ${ }^{5}$ In the USA, $\mathrm{BA}$ is produced almost in equal proportion by $B$. henselae and B. quintana.$^{13,20}$ In contrast, $B$. henselae has only recently been identified in Europe as an agent causing the disease. ${ }^{2 \mathrm{I}}$ There is a lack of information about the causative organism(s) in the other continents. From the few reports available where serious efforts were made to identify the bacteria, there is at least one unsuccessful attempt; interestingly in two immunocompetent individuals with lesions histologically mimicking BA but lacking clumps of bacilli. ${ }^{22}$ These findings leave an open door for searching for other Bartonella spp. or bacteria in BA lesions. The microbiological characterization of BA should be made, when possible, for understanding the BA etiology.

\section{Pathophysiology}

It is clear that BA is a consequence of assaults by body louse (B. quintana), cat scratch and cat fleas (B. henselae), ${ }^{2}$ and there is evidence for Bartonella spp. ability to produce angiogenic factors. ${ }^{23,24}$ Both micro-organisms have a similar 
ability to produce cutaneous lesions but, while the latter is more prone to produce liver peliosis and lymph node disease, B. quintana is associated with a greater propensity to produce bony and subcutaneous lesions. ${ }^{\circ}{ }^{\circ}$ Liver peliosis is somewhat microscopically different from BA. This difference may reflect particular characteristics of this organ such as the proportion of epithelial to mesenchymal components and the vascular pattern. ${ }^{25}$

It is unclear why $B$. henselae produces CSD in some cases and BA in others, and why B. quintana produces diseases as distinct as trench fever, endocarditis and BA. It is obvious that an as yet unidentified immunological parameter of the host influences the different clinical manifestations of these bartonelloses. While the immune status clearly affects the clinical presentation, differences in virulence among various Bartonella strains may also be responsible for the varied disease presentations. ${ }^{6}$

\section{Histopathology}

The BA histological criteria are well defined..$^{22,26,27}$ The main salient features are a lobular accumulation of rounded blood vessels with plump endothelial cells. Cell necrosis, atypia and mitoses are especially found in densely cellular areas. A mixed inflammatory cell infiltrate with predominance of neutrophils and occasional leukocytoclasia is also present. Granular eosinophilic and Warthin-Starry-positive bacilli are the hallmark of the lesion. In addition, numerous Factor XIIIa's-positive dermal dendrocytes are present in BA. ${ }^{28}$ There is indeed increasing evidence regarding the immunological activity of dermal dendritic cells and their interaction with the skin endothelium. ${ }^{29}$ The large spectrum of angiogenesis-related factors $^{3 \circ}$ might also offer new research avenues in BA.

\section{Verruga peruana}

Detailed reviews have been presented about the etiology, pathogenesis, clinical presentation and treatment of verruga peruana. ${ }^{3-34}$ Bartonella bacilliformis, the etiologic agent of the disease was the first identified member of the Bartonella genus. The disease is typically confined to Andean valleys of Peru, Colombia and the Equator, due to the ecologic distribution of its vector, the sand fly Lutzomia verrucarum. ${ }^{3}$

Verruga peruana is an eruptive angiomatous disease of the skin (Figs 3 and 4 ) that typically develops 2 months after an acute phase of bacteriemic disease known as Oroya fever or Carrion's disease. In addition to the casual presentation of the angiomatous lesions, ${ }^{28,34,35}$ malignant-looking aspects have been identified. ${ }^{36}$ There is a great histological similarity between the disease BA in HIV-positive individuals. ${ }^{37}$ However, verruga peruana differs from BA at the microscopical level, at least by the lack of aggregates of bacilli (Table 2).

Actually, verruga peruana does not seem to be confined to the recognized epidemiological villages where it was originally

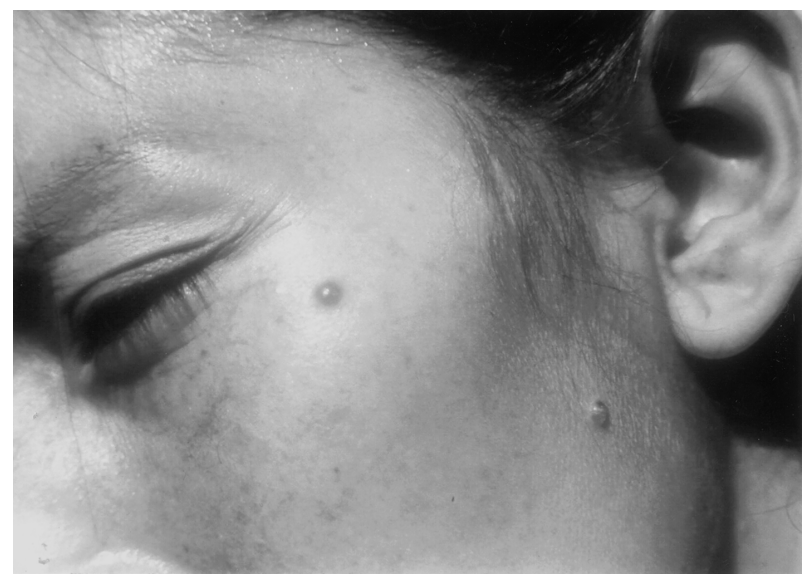

Figure 3 Verruga peruana. Two small papules on the face

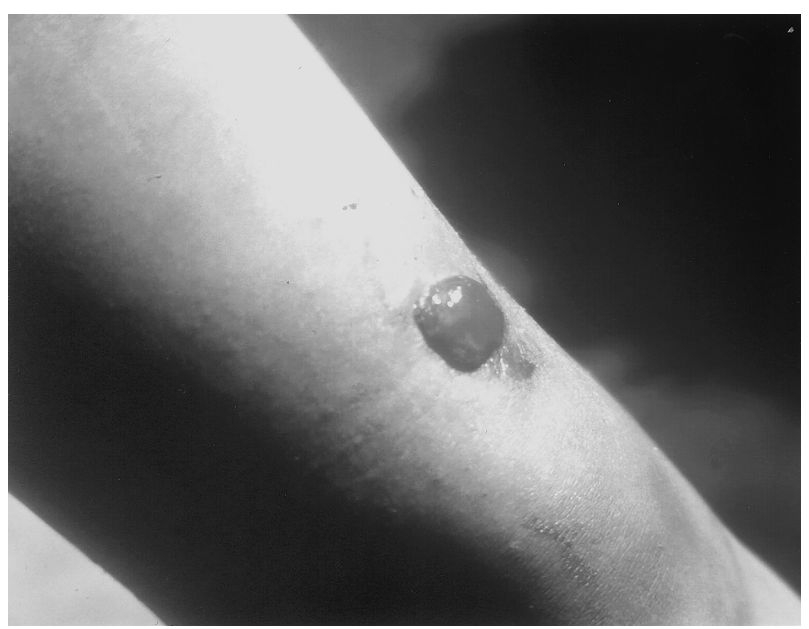

Figure 4 Verruga peruana, nodular type

documented anymore. We have indeed seen some cases of angiomatous lesions resembling verruga peruana in apparently immunocompetent individuals without any recognized risk factor including travel to verrucogenous areas and Oroya fever. As Bartonella spp. other than B. bacilliformis have been isolated from rodents in villages of Peru, ${ }^{38}$ some of these angiomatous lesions with incomplete or absent epidemiological support could represent diseases caused by Bartonella spp. different from B. bacilliformis. On the other hand, there are no documented cases regarding the occurrence of diseases caused by B. bacilliformis in HIV-infected individuals. Finally, the immunodeficiency status associated with the majority of cases of BA, mainly $\mathrm{CD}_{4}+$ lymphocyte depletion and phagocytic dysfunction, could be compared with the immunological changes produced in the Oroya fever. ${ }^{39}$ This could provide a suitable model of the influence of the immunological status on the development of some vascular lesions of the skin. 
Table 2 Similarities and differences between verruga peruana and bacillary angiomatosis

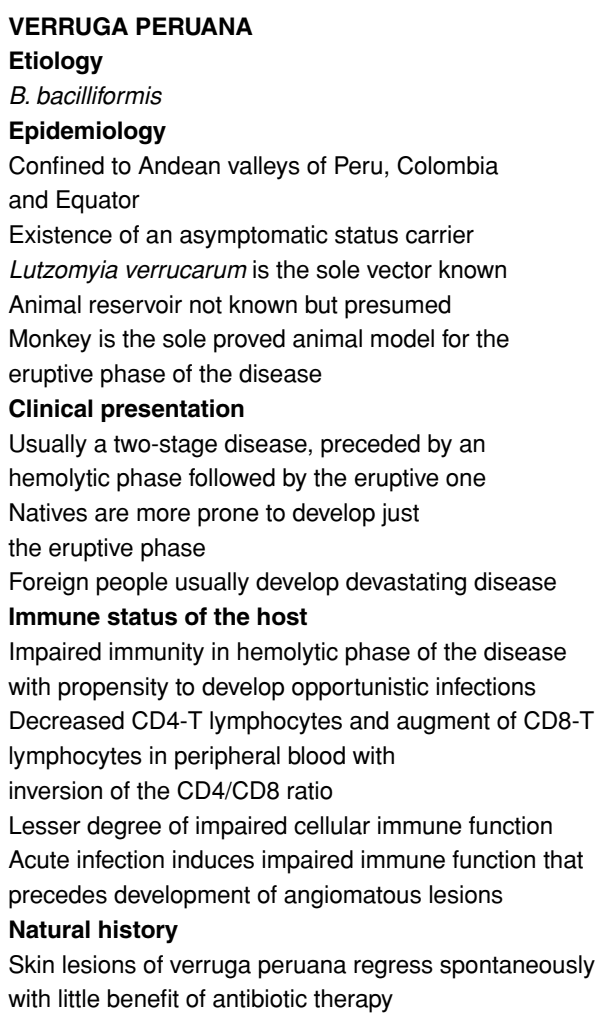

\author{
BACILLARY ANGIOMATOSIS \\ Etiology \\ B. henselae, B. quintana, other Bartonella species? \\ Epidemiology \\ Worldwide distribution \\ No healthy carrier status proved in humans \\ Body louse(also head louse) is the vector of $B$. quintana \\ Cats, in particular kittens, are the reservoir of $B$. henselae \\ No animal model has been demonstrated for $B$. quintana
}

\section{Clinical presentation}

Skin lesions occurring as papules, warts, pedunculated, subcutaneous nodules (rarely ulcerated or bleeding), or hyperkeratotic plaques

Clinically these lesions look similar to verruga peruana

\section{Immune status of the host}

The vast majority of cases occurring in HIV-positive and other immunodeficiency status, however, there are reported cases in apparently immunocompetent individuals

There is no information concerning the possible direct effect of $B$. henselae and $B$. quintana on the immune status of the host

\section{Natural history}

Lesions resolve with antimicrobial therapy, better response in immunosuppressed individuals

\section{Skin and the immune system in bartonelloses}

The skin-restricted features of verruga peruana and the predominant skin manifestations in BA together with the immunological impaired status found in both diseases make it attractive to suggest a common pathobiological pathway. The skin might be a target of specific infectious agents responsible for angiomatous diseases in the setting of impaired immune function. Indeed, angiogenesis is a biological event strictly controlled and associated with wound healing, several chronic inflammatory diseases and tumor growth and metastasis. ${ }^{40-43}$ The statement that Bartonella-associated vascular lesions may represent some variants of these angiogenic responses has already been made ${ }^{44}$ and calls for further research. The ability of Bartonella spp. to produce angiogenic factors ${ }^{24,44}$ might also be considered when analyzing the complex interaction between bacteria, skin cells and the immune system.

The immune function of the skin was emphasized many years ago under the concept of 'skin-associated lymphoid tissue' constituted by keratinocytes, Langerhans cells, T-cells and endothelial cells. ${ }^{45}$ The biological interactions between cutaneous dendritic cells, endothelial cells and skin lymphocytes is altered in some pathological conditions. For instance, there is cumulated data related to the biology of the skin in HIV-disease ${ }^{4-49}$ and the vascular proliferation in BA may represent a defect in the phagocytic function and development of granulomatous reactions such as those found in CSD.$^{50}$ In addition, B. bacilliformis tropism for the skin could be caused by the better growth of the bacilli at lower temperatures with dermal dendrocytes also playing a role. ${ }^{28,50}$

\section{Conclusion}

Bartonella spp. infections are responsible for different clinical presentations including vascular growths in the skin. Further research must be guided in order to identify the whole spectrum of the pathogens, in particular Bartonella spp. responsible for vascular lesions. The cellular and molecular components of BA and verruga peruana lesions should be scrutinized. Some analogy among these diseases could provide evidence for common biological mechanisms.

\section{References}

I Dehio C, Sander A. Bartonella as emerging pathogens. Trends Microbiol I999; 7: 226-228.

2 Maguiña C, Gotuzzo E. Bartonellosis: new and old. Infect Dis Clin NA 2000; I4: I-22. 
3 Cartihers H. Cat scratch disease. an overview based on a study of I 200 patients. Am J Dis Child I985; I39: I I 24.

4 Spach D, Koehler J. Bartonella-associated infections. Infect Dis Clin NA I998; I2: I37-I 55.

5 Tuli M, Cockerell C. Rickettsial and Bartonella infections. In. Farmer E, Hood A., eds. Pathology of the skin. New York, McGraw \& Hill 2000, 530-542.

6 Anderson B, Neuman M. Bartonella spp. as emerging human pathogens. Clin Microbiol Rev I997; 10: 203-219.

7 Fredericks D, Relman D. Sequence-based identification of microbial pathogens. a reconsideration of Koch's postulates. Clin Microbiol Rev I996; 9: I 8-33.

8 Kordick D, Hilyard E, Hadfield T, et al. Bartonella clarridgeiae, a newly recognized zoonotic pathogens causing inoculation papules, fever, and lymphadenopathy (cat scratch disease). J Clin Microbiol I997; 35: I8 13- I8 18.

9 Margileth A, Baehren D. Chest-wall abscess due to cat scratch disease (CSD) in an adult with antibodies to Bartonella clarridgeiae. case report and review of the thoracopulmonary manifestations of CSD. Clin Infect Dis I998; 27: 353-357.

Io Regnery R, Olson J, Perkins B, Bibb W. Serologic response to 'Rochalimacea henselae' antigen in suspected cat scratch disease. Lancet I992; 339: I443-I445.

I I Relman D. Has trench fever returned? N Engl J Med I995; 332: 463-464.

I 2 Stoler M, Bonfiglio T, Steigbrgel R, Pereira M. An atypical subcutaneous infection associated with acquired immunodefficiency syndrome. Am J Clin Pathol I983; 80: 7I4-7I 8 .

I3 Koehler J, Quin F, Berger T, et al. Isolation of Rochalimacea species from cutaneous and osseous lesions of bacillary angiomatosis. N Engl J Med I992; 327: I625-I63 I.

I4 Mohle-Boetani J, Koehler J, Berger T, et al. Bacillary angiomatosis and bacillary peliosis in patients infected with human immunodeficiency virus. Clinical characteristics of a case-control study. Clin Infect Dis I 996; 22: 794.

I 5 Kemper C, Lombard C, Deresinski S, et al. Visceral bacillary epithelioid angiomatosis: possible manifestations of disseminated cat scratch disease in the immunocompromised host: a report of two cases. Am J Med I990; 89: 2 I 6.

I 6 Myers S, Prose N, García J, et al. Bacillary angiomatosis in a child undergoing chemotherapy. J Pediat I992; I2I: 574.

I7 Cockerell C, Bergstresser R, Myrie W, Tierno P. Bacillary epithelioid angiomatosis occuring in a immunocompetent individual. Arch Dermatol I990; I26: 787-790.

I 8 Smith K, Skelton H, Tuur S, et al. Bacillary angiomatosis in an immunocompetent child. Am J Dermatopathol I996; I8: 597.

I9 Plettenberg A, Rasokat H, Kalibe T, et al. Bacillary angiomatosis in HIV-infected patients. An epidemiological and clinical study. In: World AIDS Conference. Geneva I998, I2: 824 .

20 Koehler J, Sánchez M, Garrido C, et al. Molecular epidemiology of Bartonella infections in patients with bacillary angiomatosis-peliosis. N Engl J Med I997; 337: I $876-$ I 883 .
2I Arvand M, Wendt C, Regnath T, et al. Characterization of Bartonella henselae isolated from bacillary angiomatosis lesions in human immunodeficiency virus-infected patient in Germany. Clin Infect Dis I998; 26: I 296- I 299.

22 Cockerell C, Le Boit P. Bacillary angiomatosis: a newly characterized pseudoneoplastic, infectous, cutaneous, vascular disorder. J Am Acad Dermatol I990; 22: 50I - 5 I 2.

23 Conley T, Slater L, Hamilton K. Rochalimacea species stimulate human endothelial cell proliferation and migration in vitro. J Laboratory Clin Med I994; I24: 52I-528.

24 Maeno N, Oda H, Yoshiie K, et al. Live Bartonella henselae enhances endothelial cell proliferation without contact. Microb Pathog I999; 27: 419-427.

25 Alkan S, Orenstein J. Bacillary peliosis hepatis. N Engl J Med I99I; 324: I 5I3-I 5I4.

26 Le Boit P, Berger T, Egbert B, et al. Bacillary angiomatosis: The histopathology and differential diagnosis of a pseudoneoplastic infection in patients with human immunodefficiency virus disease. Am J Surg Pathol I989; I3: 909-920.

27 Schwartz R, Nychay S, Janniger C, Lambert W. Bacillary angiomatosis: presentation of six patients, some with unusual features. Br J Dermatol I997; I36: 60-65.

28 Arrese J, Pierard G. Dendrocytes in verruga peruana and bacillary angiomatosis. Dermatology I992; I 84: 22-25.

29 Robert C, Fuhlbrigge RC, Kieffer D, et al. Interaction of dendritic cells with skin endothelium: a new perspective on immunosurveillance. J Exp Med I999; I89: 627-635.

30 Moretti S, Spallanzani A, Pinzi C. Skin angiogenesis; biologic basis for pathological processes. Clin Dermatol I999; I7: 629-63I.

3 I Arrese J, Maguiña C, Pierard G. La verruga peruana: pasado, presente y futuro. Piel I992; 7: 350-353.

32 Childs J, Rooney J, Cooper J, et al. Epidemiologic observations on infection with Rochalimacea among cats living in Baltimore. J Am Vet Med Assoc I994; 204: I I 75- I I78.

33 Maurin M, Raoult D. Bartonella (Rochalimacea) quintana infections. Clin Microbiol Rev I996; 9: 273-292.

34 Ellis B, Rotz L, Leake J, et al. An outbreak of acute bartonelosis (Oroya fever) In Urubamba Region Peru Am J Trop Med Hyg I999; 6I: 244-249.

35 Arias-Stella J, Lieberman P, Erlandson R, Arias-Stella J Jr. Histology, immunohistochemistry and ultrastructure of the verruga in Carrion's disease. Am J Surg Pathol I986; I0: 595-6IO.

36 Arias-Stella J, Lieberman P, Garcia-Cáceres U, et al. Verruga peruana mimicking malignant neoplasms. Am J Dermatopathol I987; 9: 279-291.

37 Le Boit P, Berter T, Egbert B, et al. Epithelioid hemangiomalike vascular proliferation in AIDS. Manifestation of cat-scratch disease bacillus or infection? Lancet I 988; I: 960-963.

38 Birtles R, Canales J, Ventosilla R, et al. Survey of Bartonella species infecting intradomicillary animals in the Huayllacallan Valley, Ancash, Peru, a region endemic for human bartonellosis. Am J Trop Med Hyg I 999; 60: 799-905. 
39 Patrucco R. Estudio de los parámetros inmunológicos en pacientes portadores de la enfermedad de Carrion (Bartonelosis humana) Diagnóstico I983; I2: I38-I44.

40 Rossi D, Zlotnik A. The biology of chemokines and their receptors. Ann Rev Immunol 2000; I 8: 217-242.

4I Keane M, Arenberg D, Lynch J, et al. The CXC chemokines, IL-8 and IP-IO, regulate angiogenic activity in idiopathic pulmonary fibrosis. J Immunol I997; I59: I437-I443.

42 Piérard GE, Piérard-Franchimont C. Stochastic relationship between the growth fraction and vascularity of thin malignant melanomas. Eur J Cancer I997; 33: I 888-I892.

43 Heymans O, Blacher S, Brouers F, Pierard GE. Fractal quantification of the microvasculature heterogeneity in cutaneous melanoma. Dermatology I999; I98: 2 I 2-2 I7.

44 Garcia F, Wojta J, Broadley K, et al. Bartonella bacilliformis stimulates endothelial cells in vitro and is angiogenic in vivo. Am J Pathol I990; I36: I I25-II35.
45 Streilein J. Lymphocyte traffic, T-cell malignancies and the skin. J Invest Dermatol I978; 7I: I67-I7I.

46 Duvic M. Human immunodeficiency virus and the skin: selected controversies. J Invest Dermatol I995; I05: I I 7 S-I 2 IS.

47 Memar O, Arany I, Tyring S. Skin-associated lymphoid tissue in human immunodeficiency virus-I, human papilomavirus, and herpes simplex virus infections. J Invest Dermatol I995; 105: 99S-104S.

48 Steinman R. The dendritic cell in clinical immunology: the AIDS example. J Laboratory Clin Med I996; I28: 53 I- 535.

49 Pope M. Mucosal dendritic cells and immunodeficiency viruses. J Infect Dis I999; I79: $\mathrm{S}_{427}-\mathrm{S}_{43}$.

50 Karem K, Paddock C, Regnery R. Bartonella benselae, B. quintana, and B. bacilliformis: historical pathogens of emerging significance. Microb Infect 2000; 2: II93-I 205. 